\title{
What does God have to do with my health?
}

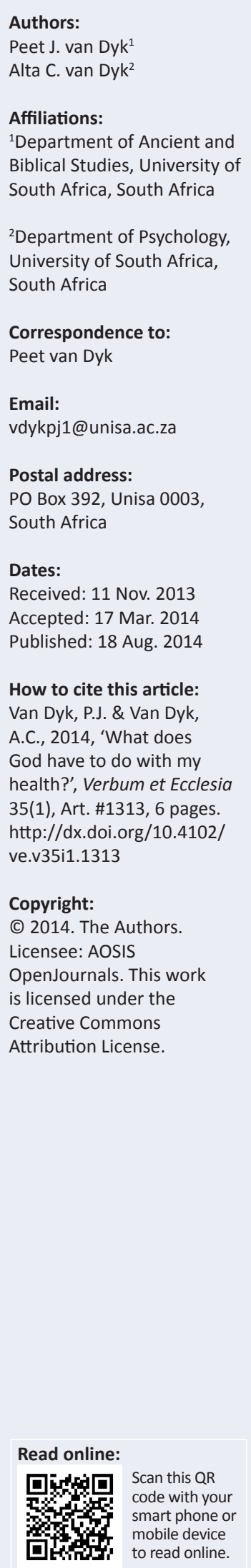

Perceptions about God's involvement in the health of people have always been an issue in Christianity. Conflicting views regarding the transcendent versus immanent nature of God have therefore played a prominent part within theological discussions. The purpose of this empirical survey was to explore the extent to which South African Christians directly attribute their health and/or diseases to the hand of God. A total of 3000 structured questionnaires were distributed of which 575 were received back. The IBM Statistical Package for the Social Sciences (SPSS 21) statistical program was used to analyse the data. Most participants disagreed with the view that God largely determined their health, although the majority did think that diseases (including AIDS) were sent by God, whilst playing down the role of natural causes. In conclusion, one could say that health beliefs amongst South Africans are closely linked to supernatural agents, although the direct role of God is seen mostly in terms of the sending of occasional diseases rather than constant involvement in general health.

Intradisciplinary and/or interdisciplinary implications: The study challenges the applicability of a secularised medical model within the South African context and its relevance for prevention programmes.

\section{Introduction}

Nowhere is the question regarding God's involvement in the everyday life of Christian believers more acute than in the field of health and disease. In the biblical book of Job the main character's misfortune extended inter alia to his ill health (Job 2:4-8). Throughout the Old Testament God's blessings to the individual were regularly associated with longevity, offspring and health (Hasel 1983:191-192). Healing and prevention from diseases were therefore seen as basic interventions made by God in the life of believers in the Old Testament (Hasel 1983:197; cf. e.g. Ps 41:3; 147:3; Is $53: 5 ; 58: 8 ; \mathrm{Jr} 17: 14)$. In the New Testament the importance of healing is further illustrated by the fact that a significant aspect of Jesus' work on the earth was seen to be the healing of the sick (e.g. Mt 8:8; 8:16; 9:35; 19:2; Mk 5:34; Lk 8:50; 5:17; 9:11). The importance of Jesus' healing function is further strongly emphasised by Craffert (2008:245-260) when he describes Jesus as a typical Shamanic figure with healing powers. Craffert further acknowledges the fact that Jesus' healing powers were at least partially seen in terms of 'ancient techniques or practices that were wellknown in magical circles' (Craffert 2008:292).

The questions about health and disease and the possible role God may play in these aspects of our lives, are especially relevant in the current milieu where secularisation is taking place worldwide (cf. Nieder-Heitmann 2003:139-191; Knebelkamp 2003:192-199; Sebastian 2003:204-211). The process of secularisation is closely linked to the perception of how directly the Christian God is active in human affairs and hence to what degree he is perceived as an immanent rather than a transcendent God (cf. Cline n.d.). Scholars have disagreed extensively over this matter during the ages. For example, Kierkegaard (cf. McDonald 2012; Cline n.d.) and Vahanian (1961:14-15), argued strongly for the return to a more transcendental view of God and viewed the present emphasis on an immanent God as a corruption of the biblical view. In contrast to them Paul Tillich (Cline n.d.; Tillich 1951:235ff.) advocated strongly for an immanent God as underlying his panentheistic theology.

The perceived role God plays in our everyday lives and health is largely determined by our world view. Although it is accepted by many scholars that such a world view is a social construct (cf. Berger \& Luckmann 1967) it should nonetheless be acknowledged that most people maintain the conviction that their world view is closely linked to an independently existing reality (i.e. realism). This is equally true in the case of the prescientific magico-mythical world view (as was prevalent in ancient and biblical times - cf. Van Dyk 2011:422-444) and in current positivist philosophical circles. 
The purpose and focus of this research was to assess the extent to which South Africans believe that health and/or diseases are regulated by God, versus the role attributed to mere natural causes and how these views may impact on health care programmes. The views of South Africans were assessed via a country-wide survey, which formed part of a larger research project regarding the perceived role of supernatural forces (including God, the ancestors and magic) as determinants of health and disease.

Health beliefs are important when implementing medical prevention and health care programmes (e.g. the antiretroviral [ARV] programmes in the current AIDS context), because these health beliefs may play a vital role in the potential success of such programmes. Health beliefs are important determinants of behavioural change within the health care environment, in so far as they influence the perceptions of patients or clients with regard to the effectiveness of prevention strategies, medical care and medications (cf. Langley 1977:244-260; Lau, Quadrel \& Hartman 1990:240-259). Knowledge about the health beliefs of their patients may therefore be of critical importance to health care workers in South Africa when planning effective prevention strategies and promoting personal health.

\section{Research method and design}

An empirical survey was conducted amongst the South African population from various backgrounds and geographical locations. The survey formed part of a larger study regarding health beliefs and how such beliefs may inform our health care system.

\section{Sample}

Questionnaires were sent to approximately 3000 psychology students at the University of South Africa as part of a noncompulsory assignment in which they were requested to act as voluntary field workers. They were explicitly requested not to fill in the questionnaires themselves but to give the questionnaire to two people from different backgrounds and educational levels within their community. In addition to this, Zulu field workers were trained to conduct a survey with the same questionnaires in rural KwaZulu-Natal, South Africa. The total sample therefore included respondents from diverse backgrounds and could be described as a convenient sample (cf. Coolican 2004:42). Sampling attempted to avoid any bias in terms of gender, age, occupation or geographic location.

Participants were assured that their anonymity would be protected and they were requested not to write their names on the completed questionnaires, whilst fieldworkers were asked to seal the completed questionnaire in an envelope (in the presence of the participant) and send them to the researchers without opening them.

\section{Measuring instrument: Structured questionnaire}

A structured questionnaire was used for the survey where participants had only to mark the answer of their choice.
Participants were explicitly instructed that there are no right or wrong answers, but that the purpose of the survey was to determine their own personal opinions and beliefs. The following information was obtained from the questionnaire:

- Demographical information (i.e. age, gender, place of residence, home language, highest academic qualification, occupation and religion).

- Likert scales (ordinal three-point scales, ranging from 'agree' to 'disagree') were used to measure participants' religious and health beliefs. Three categories of questions were asked: (1) perceived causes of diseases, including AIDS (Questions 1-5 and 17-22), (2) determinants of health (Questions 6-9) and (3) perceived power of medicines (Questions 10-16 and 23-30).

\section{Statistical analysis}

The IBM Statistical Package for the Social Sciences (SPSS 21) was used for descriptive and inferential statistical analysis of the data. The three-point Likert items (Questions 1-30) were coded to range from +1 (agree) to -1 (disagree). This implies that positive values would indicate agreement with a specific statement - zero values would reflect uncertainty, whilst negative values would reflect disagreement.

Based on Principal Component Analysis (PCA) (the data adhered to all the requirements for PCA) two scales (i.e. a health and a disease scale) were calculated by summing up the values of the individual questions and by dividing the results by the number of questions in each scale. This yielded values for each scale between +1 and -1 . The reliability of both the health scale and the disease scale were within acceptable limits (i.e. health scale: Cronbach's Alpha =0.775; disease scale: Cronbach's Alpha $=0.636)$. When tested for normality (Kolmogorov-Smirnov test) both scales yielded a significant result, indicating that the scales do not adhere to normality (cf. Pallant 2013:66), necessitating the usage of nonparametric tests in analysing the data (i.e. Mann-Withney $U$ tests) (cf. Pallant 2013:221; Coolican 2004:363). The level of significance was set at 0.05 and only medium and high effect sizes were reported (cf. Pallant 2013:218).

\section{Results}

\section{Demographic attributes of participants}

A total of 575 participants returned questionnaires, representing a return rate of $19.2 \%$. Of the participants $62.1 \%$ were women and $37.7 \%$ men. The mean age of participants was 34.8 years $(\mathrm{SD}=11.5 ; n=575)$. The majority of the participants $(62.6 \%)$ resided in cities or towns, whilst $37.2 \%$ stayed in rural areas. Most of the participants (71.8\%) spoke a black African language at home, whilst 27.5\% spoke other languages. Educational levels of the participants were as follows: $8.9 \%$ had Grade 7 or lower; $22.3 \%$ had between Grade 8 and 11; 37.9\% had matric and 30.3\% had a postmatric qualification.

Religious affiliations were broadly classified into two main categories: (1) 'mainline Christian' and (2) 'traditional 
African'. For the purpose of this study 'mainline Christian' was defined as not belonging to one of the African Initiated churches, whilst the 'traditional African' group included African Initiated churches (e.g. Zionist or Shembe) as well as people adhering to traditional African religion. Due to their small numbers, participants who belonged to other religions or who indicated that they were non-religious, were ignored for the purposes of calculations involving religious affiliation. Of the 537 respondents who were included in the calculations, 59.3\% (341) were affiliated to mainline Christian churches, whilst $34.1 \%$ (196) belonged to traditional African religious affiliations.

\section{My health is largely determined by God}

The calculated health scale, linking God and general health, yielded a negative result with $63.2 \%$ of the respondents disagreeing with the view that their health is largely determined by God, whilst $11.3 \%$ were uncertain and only $25.6 \%$ agreed with the statement.

Significant intergroup differences were observed with regard to perceptions about God's involvement in general health. Participants with an African home language and those coming from rural communities disagreed more with the view that God is an important determinant of our health than those who speak a non-African home language or participants living in cities and towns respectively (see Table 1).

These results suggest that God was perceived by most participants (almost two thirds) as a 'high God', being more transcendent than immanent. God therefore does not micro-manage our general health or well-being (although other supernatural forces may be involved). The fact that this perception about God as a 'distant' God was especially popular amongst respondents from rural communities and amongst those speaking an African language, may suggest that the idea of a distant or 'higher' God was more prevalent in African communities and amongst those living in rural areas.

This concept of a high or transcendent God (as perceived by most participants) should not be seen as a sign of secularisation in the sense that God (or other supernatural agents) plays no role in human life. This is suggested by the following facts: (1) almost all the participants (96.8\%) indicated that they belonged to a religious institution, (2) most participants did recognise God's hand in the prevalence of disease (see discussion below) and (3) other supernatural agents (the ancestors and magic) were also identified by many participants as important factors in causing diseases and as determinants of health.

\section{Diseases (including AIDS) are caused by God}

Although general health was not perceived as being determined by God, God was nonetheless perceived by most respondents as being instrumental in causing diseases. On the calculated disease scale, more than $70 \%(71.3 \%)$ of the respondents viewed God as the primary cause of diseases including AIDS - whilst only $12.1 \%$ disagreed with the view. Participants belonging to mainline churches (as opposed to those who belong to more traditional African institutions) were significantly more convinced that diseases are caused by God (see Table 2). This intergroup difference can probably be explained by the fact that participants from more traditional African backgrounds were more inclined to attribute disease not only to God, but also to other supernatural causes such as the ancestors and magic or witchcraft.

The fact that respondents were willing to directly attribute occasional health calamities such as diseases to God, but did not attribute general health directly to God, is an interesting find. It may suggest that God is seen by most participants as somebody who occasionally intervenes into our lives, without implying that he is constantly involved in our daily lives. This is in accordance with viewing God as a more distant, transcendent or high God, rather than a more immanent God, dictating the smallest detail of our lives.

The view that God occasionally intercedes in the lives of people by sending diseases, introduces the theological problem of why God would send such diseases to afflict people: is it as punishment for $\sin$ (the ideology of retribution) (cf. Habel 1985:60-69)? The fact that participants in the study probably saw diseases as a punishment for sin may be an indication that the ideology of retribution is also prevalent amongst South African Christians. This is notwithstanding the fact that some strands within the Bible are critical of the tendency to directly attributing specific diseases to specific sins (cf. Habel 1985:60-69; the book of Job and the reaction of Jesus in John 9:1-3 regarding the man who was blind since his birth).

\section{Natural causes}

In addition to the health and disease scales (discussed above) four additional statements in the survey pertained specifically to natural causes (as opposed to supernatural ones) as determinants of health, diseases and in the healing power of medicines and herbs. These questions will be discussed next. ${ }^{1}$

1.An attempt to combine the four questions into one scale was not successful because it yielded a low reliability (Cronbach's Alpha $=0.3$ ).

TABLE 1: Intergroup differences on health scale (Mann-Whitney $U$ Tests).

\begin{tabular}{llllll}
\hline Group & $\boldsymbol{n}$ & Mean & $\boldsymbol{U}$ & $\boldsymbol{Z}$ & $\boldsymbol{P}$ \\
\hline African languages & 400 & -0.41 & 22245 & -5.350 & 0.000 \\
Other languages & 156 & -0.02 & - & - & - \\
Rural & 209 & -0.42 & 31222 & -2.946 & 0.003 \\
Town or city & 350 & -0.23 & - & - & - \\
\hline
\end{tabular}

TABLE 2: Intergroup differences on disease scale (Mann-Whitney $U$ Tests).

\begin{tabular}{lllllll}
\hline Group & $\boldsymbol{n}$ & Mean & $\boldsymbol{U}$ & $\boldsymbol{Z}$ & $\boldsymbol{P}$ & Effect Size \\
\hline $\begin{array}{l}\text { Mainline } \\
\text { churches }\end{array}$ & 337 & +0.58 & 29053 & -2.344 & 0.019 & Medium \\
$\begin{array}{l}\text { Traditional } \\
\text { African }\end{array}$ & 194 & +0.47 & - & - & - & - \\
\hline
\end{tabular}




\section{Diseases are caused by germs only}

This statement specifically assessed if participants saw diseases mainly as being caused by germs or infective agents and not as primarily being caused by God or other supernatural forces. Half of the participants (50.1\%) agreed with the statement, whilst $19.7 \%$ were uncertain and $29.4 \%$ disagreed. No intergroup differences were observed.

This result may suggest that half of the participants at least thought that germs had something to do with diseases, although the role of supernatural agents, using germs to cause diseases can probably not be ruled out even in this group. The fact that the other half of the participants was uncertain or disagreed with the statement is a further indication to what extent the participants were not willing to see disease merely as a neutral or random occurrence, but were inclined to look for supernatural causes like most traditional Africans (cf. Mbiti 1969:165, 195).

\section{Our health is primarily determined by our own choices}

This question queried to what extent participants thought that health was primarily determined by own choices, that is, if health is a matter of internal locus of control, or alternatively could be attributed to external factors beyond their control (cf. McGraw-Hill 2002). More than three quarters (75.3\%) of the participants disagreed with the statement that own choices determine health, with a mere $11.1 \%$ being uncertain and $12.7 \%$ who agreed with the statement. This result suggests that by far the majority of participants thought that they had no, or only limited control over their personal health. Logically this implies that they therefore thought that their health was largely determined by external factors beyond their own control. To what extent they regarded these external factors influencing their health as being random circumstances or alternatively were caused by supernatural agents, was not directly assessed, but the fact that the majority of participants were inclined to think that God or other supernatural agents were involved in diseases, strongly suggests that they thought that their control over their own health was limited due to the role of such supernatural agents. This view further implies that participants would to a large extent see themselves as disempowered and rendered more or less helpless in the face of diseases. Although diseases such as flu and colds are of course difficult to avoid by anyone, it is nonetheless disturbing that this 'helplessness' in the face of diseases is also generalised with regard to diseases such as AIDS (see discussion below).

\section{The power of medicines and herbs are primarily determined by their chemical properties}

Less than $20 \%(19.8 \%)$ of the respondents agreed with the statement that medicines and herbs derived their power from their chemical properties, whilst more than half (52.0\%) of the participants disagreed and $27.7 \%$ were uncertain about the statement. This result may be surprising to many health care workers, trained in the Western Medical Model, but it clearly suggests that the power or effectiveness of medicines and herbs was not seen in terms of their chemical or natural properties (as assumed by Western medicine), but was rather seen in terms of their supernatural properties.

\section{People contract AIDS because they took a chance with unprotected sex}

The above statement assessed the participants' knowledge about the primary way of HIV transmission in Africa. The fact that $80.7 \%$ disagreed with the statement that HIV transmission is mostly caused by unprotected sex, whilst $5.2 \%$ were uncertain and only $13.6 \%$ agreed with the statement, may be surprising to many researchers and health care workers. This result suggests that participants were either uninformed about the primary way of HIV transmission (which is extremely alarming in the midst of our current AIDS pandemic) and/or that the causes of diseases in Africa are seldom seen in terms of natural causes only (Boahene 1996:609-616; Mbiti 1969:165, 195). This is in line with the finding that $76.3 \%$ of the respondents viewed God as the primary cause of diseases.

\section{Discussion}

The results of the research revealed three major trends in the beliefs regarding health of the respondents: (1) most respondents did not think that God played an important role in micro-managing their general health, (2) contrary to the first belief, the majority of respondents attributed diseases to the hand of God and (3) natural factors were not considered important in causing diseases. This complex picture of beliefs about health amongst South Africans can best be explained by two factors. Firstly, that God was seen by most respondents as a transcendent (far away high) God and secondly, that most respondents did not believe in the modern scientific world view, but rather held a prescientific magico-mythical world view.

In traditional African communities the high God (or sky God) is perceived - like amongst most other ancient or prescientific communities - as an utterly transcendent God, who does not micro-manage people's lives on a constant basis (Encyclopaedia Britannica n.d.). It is, however, important to realise that even in the case of a God, perceived as being transcendent, this does not completely exclude the possibility that he may occasionally send diseases to punish sins or to test people's faith. Especially epidemics and serious diseases (e.g. AIDS) may be attributed to a high or transcendent God. The results of the survey therefore suggest that the views of most respondents regarding God (and his involvement in general health issues and diseases) were congruent with traditional African beliefs in a high or transcendent God.

The second factor (i.e. the belief in a magico-mythical world view) would explain the lack of emphasis on natural causes and effects amongst respondents. According to the majority of respondents diseases are not caused by germs only, health is not primarily the result of our own choices, medicines and herbs do not derive their effectiveness from their chemical properties and it is not unprotected sex that is the main cause of HIV transmission. Although these views may seem 
inexplicable from the perspective of a scientific Western Medical Model they are completely congruent with a magico-mythical world view. A magico-mythical world view is deeply religious in the sense that natural or physical causes are considered far less important than supernatural forces. These supernatural forces usually include God (as suggested in this survey by the fact that he may send diseases), but also by other supernatural agents, for example the ancestors or magical forces. Unfortunately such a world view is also largely based on an external locus of control, in which people do not take responsibility for their own health.

In the South African situation this implies that when implementing prevention and wellness programmes a clash between the Western Medical Model (largely accepted by health care professionals) versus the magico-mythical world view (often accepted by patients) may cause a serious breakdown in communication between health care professionals and their patients. This incongruence would necessarily impact negatively on the success of such programmes. For example, to only emphasise natural causes in explaining diseases, whilst ignoring the possible role of God (or other supernatural forces) would be deemed insufficient by most patients with a traditional religious framework. Similarly the mere emphasis on the chemical abilities of ARVs, the advantages of healthy lifestyle choices, or the dangers of unprotected sex, would most probably not convince most patients to adhere to their medication, or to change their high risk behaviour. They would be far more interested in the possible role of supernatural forces that may be involved in these processes.

The possible solutions to this problem are by no means straight forward and no quick solutions are possible. Logically, two extreme solutions can be suggested: firstly, from a more realist philosophical position, it may be argued that the 'outdated' magico-mythical world view of patients should deliberately and consistently be challenged and that patients should be properly educated in the Western Medical Model based on physical causes and effects. Preferably this Western Medical Model should not only emphasise biomedical aspects, but consist of a more comprehensive bio-psychosocial model, which also includes psychosocial causes of diseases (cf. Craffert 2008:260-271). It should therefore be the task of health care professionals to inform their patients about the scientific medical model so that they could comprehend the physical and psychosocial (i.e. natural) causes of diseases and the effectiveness of health care procedures and medicines.

Contrary to the realist framework described above, a more relativistic philosophical framework (where not one world view is regarded as superior to another and one's own world view is thereby relativised) would suggest that the religious (magico-mythical) world view of patients should rather be respected by health care professionals. In practical terms this implies that health care professionals should persuade their patients about the possible benefits of health care practices and medication by also referring to the possible supernatural forces involved in such procedures or medication.

\section{Conclusion}

Arguing from a critical realist position (cf. Richard 2009) we would like to suggest that both these extreme positions are problematic. The relativist position is flawed because it often ignores the obvious benefits and successes of the Western Medical Model. More extreme examples of this relativist position become especially unacceptable when these imply that we should revert back to a prescientific world view where health issues are mostly seen in magico-religious terms and natural causes and effects are neglected or denied.

On the other hand, the more realist view suggest that the magico-mythical world view of the general populace could be changed to a scientific world view within a few educational sessions, or that rational convictions necessarily linked to deeply held emotional beliefs, should be regarded as both unrealistic and naïve. World views can be changed through education, but they seldom if ever change overnight. More often such changes are gradual and even when rational convictions have been changed, non-rational beliefs may still persist within a community (e.g. beliefs in magic). Such nonrational beliefs may play an important psychological role in the healing process (both in the cases of psycho-immune responses and psychosomatic diseases) as is strongly argued in the field of Psychoneuroimmunology (cf. Ader 2007). It is therefore important for patients to really believe in medical interventions before they will adhere to their medication or in some cases for such interventions to be successful.

In the light of the above arguments a more pragmatic approach to the problem may in the short term yield the best results. That is, whilst gradually educating the general populace about natural causes and effects, some acknowledgement of traditional religious beliefs, regarding health and diseases, may be appropriate within the health care environment. It is therefore important that the possible role of God in health issues should be acknowledged or at least be respected. Health care professionals can, for example, emphasise the notion that the same God 'who sends diseases' is also the God who empowers the health care system to provide effective treatment for diseases. Such an emphasis should, however, never deny the importance of physical causes or imply that one could shirk one's responsibilities with regard to one's own health.

\section{Acknowledgements Competing interests}

The authors declare that they have no financial or personal relationship(s) that may have inappropriately influenced them in writing this article.

\section{Authors' contributions}

P.J.v.D. (University of South Africa) was the project leader A.C.v.D. (University of South Africa) was responsible for project design and most of the statistical analysis. 


\section{References}

Ader, R., 2007, Psychoneuroimmunology, 4th edn., Elsevier Academic Press, Burlington, MA.

Boahene, K., 1996, 'The IX international conference on Aids and STD in Africa', AIDS Care 8(5), 609-616. http://dx.doi.org/10.1080/09540129650125560

Berger, P.L. \& Luckmann, T., 1967, The social construction of reality: A treatise in the sociology of knowledge, Penguin, Harmondsworth.

Cline, A., n.d., God is transcendent \& immanent, viewed 30 October 2013, from http:// atheism.about.com/od/whatisgod/a/ transcendent.htm

Coolican, H., 2004, Research methods and statistics in Psychology, 4th edn., Hodder \& Stoughton, London. PMid:15094139

Craffert, P.F., 2008, The life of a Galilean Shaman. Jesus of Nazareth in anthropological historical perspective, Cascade Books, Eugene, OR.

Encyclopaedia Britannica, n.d., s.v. High God, viewed 17 February 2014, from http:// global.britannica.com/EBchecked/topic/265232/High-God

Habel, N.C., 1985, The book of Job: A biblical commentary, Westminster Press, Philadelphia.

Hasel, G.F., 1983, 'Health and healing in the Old Testament', Andrews University Seminary Studies 21(3), 191-202.

Knebelkamp, A., 2003, 'Believing without belonging? In search of new paradigms of church and mission in secularized and postmodern contexts: Brazilian insights and "outsights"', International Review of Mission 92(365), 192-199. http://dx.doi. org/10.1111/j.1758-6631.2003.tb00394.x

Langley, J.K., 1977, 'Social networks, health beliefs, and preventative health behaviour', Journal of Health and Social Behavior 18, 244-260. http://dx.doi. org/10.2307/2136352
Lau, R.R., Quadrel, M.J. \& Hartman, K.A., 1990, 'Development and change of young adults' preventative health beliefs and behaviour: Influence from parents
and peers', Journal of Health and Social Behavior 31, 240-259. http://dx.doi. and peers', Journal of

Mbiti, J.S., 1969, African religions and philosophy, Heinemann, London.

McDonald, W., 2012, s.v. 'Søren Kierkegaard', in The Stanford Encyclopedia of Philosophy, viewed 17 February 2014, from http://www.plato.stanford.edu/ archives/fall2012/entries/kierkegaard/

McGraw-Hill, Health and human performance, 2002, Health locus of control I, viewed 05 November 2013, from http://www.mhhe.com/catalogs/sem/hhp/faculty/ labs/index.mhtml?file=/catalogs/sem/hhp/labs/health/05

Nieder-Heitmann, J.H., 2003, 'The missionary challenge of Christendom and modernity in South Africa: A Dutch Reformed account', International Review of Mission 92(365), 139-191. http://dx.doi.org/10.1111/j.1758-6631.2003. tb00393.x

Pallant, J., 2013, SPSS survival manual: A step by step guide to data analysis using SPSS for Windows, 5th edn., McGraw Hill, Berkshire.

Richard, J.R., 2009, s.v. 'Moral Anti-Realism', in The Stanford Encyclopedia of Philosophy viewed 17 February 2014, from http://plato.stanford.edu/archives/sum2009/ entries/moral-anti-realism/

Sebastian, J.J., 2003, 'Believing and belonging: Secularism and religion in India', International Review of Mission 92(365), 204-211. http://dx.doi. org/10.1111/j.1758-6631.2003.tb00396.x

Tillich, P., 1951, Systematic theology , vol. 1, University of Chicago Press, Chicago.

Vahanian, G., 1961, The death of God. The culture of our post-Christian era, George Braziller, New York.

Van Dyk, P.J., 2011, 'Significant versus symbolic universes - Sorting out the terminology', Journal for Semitics 20(2), 422-444. 